\title{
Visualizing Relative Humidity
}

\section{A. E. Parkings}

To cite this article: A. E. Parkings (1919) Visualizing Relative Humidity, Journal of Geography, 18:7, 275-280, DOI: $10.1080 / 00221341908984831$

To link to this article: http://dx.doi.org/10.1080/00221341908984831

册 Published online: 22 Feb 2008.

Submit your article to this journal $\pi$

Џll Article views: 4

Q View related articles $₫$

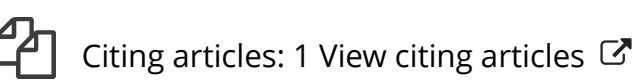




\title{
VISUALIZING RELATIVE HUMIDITY
}

\author{
By A. E. PARKINS \\ George Peabody College for Teachers, Nashville, Tenn.
}

Most students attacking the study of moisture for the first time find difficulty in understanding the problems commonly considered in a discussion of relative humidity. This difficulty is due chiefly to the invisibility of the material under consideration and is particularly evident among students who have had little training in the physical sciences. The writer for the last three or four years has found the scheme described below of great value in aiding the student to visualize the terms used and to visualize the changes in the actual (absolute), possible, and relative humidity that take place as the air is heated or cooled.

\section{Visualizing the Terms Used}

1. The capacity of a given space for water vapor (also known as the possible humidity) depends upon the temperature. The possible humidity increases with increasing temperature and, moreover, increases at an increasing rate. This capacity is expressed in grains per cubic foot of saturated air.

The possible humidity at $-10^{\circ}, 0^{\circ}, 10^{\circ}, 20^{\circ}$, etc., of temperature may be visualized by a diagram representing a series of jars of equal cross section. In Figure 1 the height of each jar is proportional to the number of grains of water vapor held. The capacity of a cubic foot of air at $-10^{\circ}$ is only .35 grains. In the diagram this is represented by a small jar (A, Fig. 1). At $50^{\circ}$ the possible water vapor that may be contained in a cubic foot of space is 4.09 grains. This is represented by a jar of medium height (G, Fig. 1). At a temperature of $100^{\circ}$ the capacity is 19.79 grains, which is represented by a tall jar (L, Fig. 1).

What happens to the possible humidity, or, according to our scheme of visualizing, to the height of the jar, when the air is warmed? Suppose air at $10^{\circ}$ (C, Fig. 1) is warmed to $50^{\circ}(\mathrm{G}$, Fig. 1), the capacity is increased from .84 grains of water vapor per cubic foot to 4.09 grains per cubic foot. This increase in capacity may be visualized by imagining that the sides of the 
jar are pushed up. If the air is warmed to $70^{\circ}$, the sides have gone up so that the capacity has become 7.9 grains. If warmed to $100^{\circ}$, there is a further extension so that the capacity has become 19.79 grains.

In a similar way cooling air may be thought of as a lowering of the sides of the jar-a reduction of the capacity, therefore.

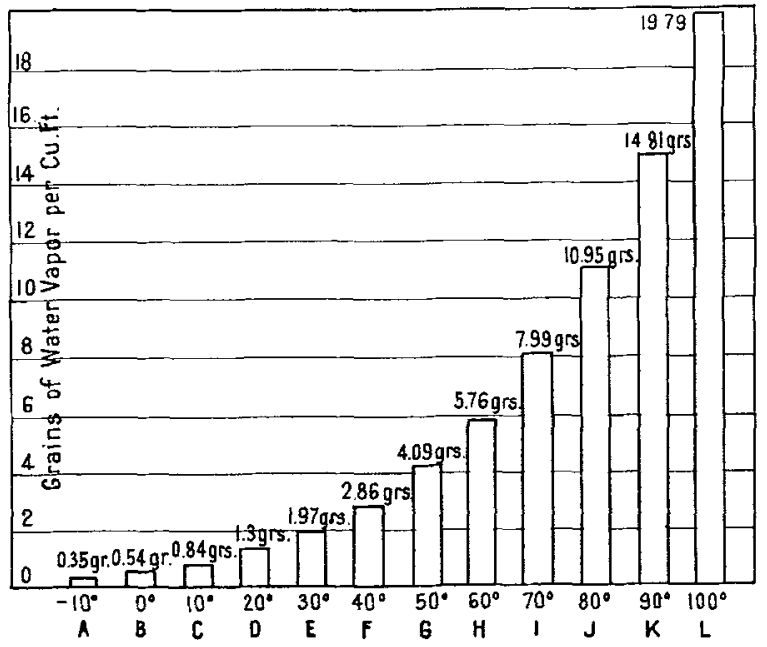

Fra, 1-Diagram showing the capacity of air for water vapor (possible humidity) at successive temperatures. L., capacity at $100^{\circ}$, reads 19.79 .

grains of water vapor per cubic foot.

3. Relative humidity is the "percentage of fullness." It is the ratio of the actual to the possible. Relative humidity is expressed in percentag'e. Air with a relative humidity of 100 per cent is saturated.

The relation of the possible, actual, and relative humidity may be visualized readily. In Figure 2 the jar $G$ represents the capacity (or the possible) of the air at $50^{\circ}$. This is 4.09 grains of water vapor. But the jar is only half full (2.04 grains). The relative humidity is, therefore, 50 per cent. Similarly L (Fig. 2) is half full, and the relative humidity is then 50 per cent; but in this case the actual is much larger, being equal to 50 per cent of 19.79 grains, or 9.895 grains. In $\mathrm{C}$ the relative humidity is 75 per cent since the jar is three-fourths full. The possible humidity is .84 grains, and the actual three-fourths of .84 , or .63 
grains. A comparison of $\mathrm{C}$ with either $\mathrm{G}$ or $\mathrm{L}$ shows that air with a relative humidity of 75 per cent may contain much less water vapor than air with a relative humidity of 50 per cent. Air in Greenland, with a relative humidity of 90 per cent, contains much less water vapor than air in the Sahara, with a humidity of 20 per cent. (Compare, for example, $\mathrm{C}$ and $\mathrm{K}$ in Fig. 2.)
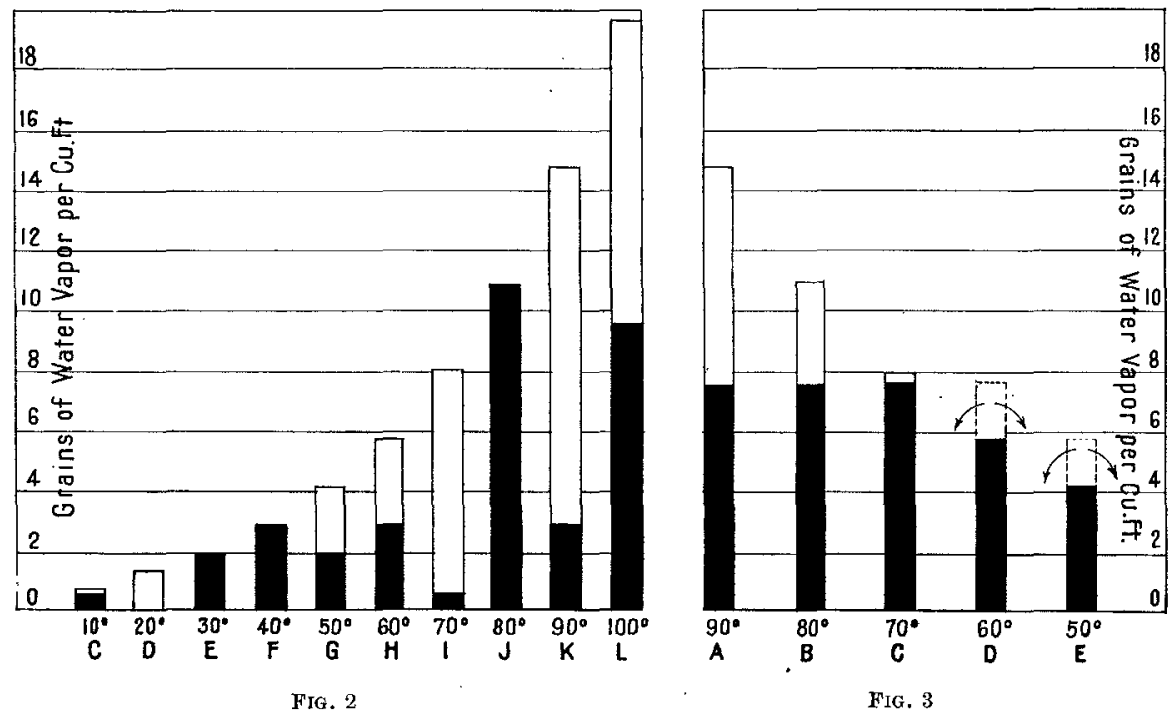

FIG. 2-Diagram illustrating the effect of the heating of air on the relative humidity. See the text for explanation.

Frg. 3-Diagram illustrating the effect of the cooling of air on the relative humidity. See the text for explanation.

Jars E, F, and $\mathrm{J}$ (Fig. 2) represent saturated air at $30^{\circ}, 40^{\circ}$, and $80^{\circ}$ respectively. Jars $\mathrm{C}$ and $\mathrm{I}$ have the same actual but vastly different relative humidities, because the possible humidity of $I$ is 7.99 grains while that of $\mathrm{C}$ is but .84 grains.

Effect of the Heating of Air on the Relative Humidity

What effect does heating air have on its relative humidity? Let us suppose saturated air at $40^{\circ}$. (F, Fig. 2) is heated gradually to $90^{\circ}$. Heating air, as earlier shown, increases the capacity, that is the sides of the jar rise. Since in the heating it is assumed that no water vapor is added, by the time a temperature of $60^{\circ}$ is reached (H, Fig. 2) the relative humidity has been reduced about 50 per cent; for at $60^{\circ}$ the capacity (or possible humidity) is 5.76 grains and the actual humidity is 2.86 grains. The jar 
$(\mathrm{H})$ is shown to be about half full. At a temperature of $90^{\circ}$ (K, Fig. 2) the capacity has reached 14.81 grains (the sides of the jar have risen), and, since the actual humidity remains the same, the relative humidity is 2.86 divided by 14.18 , or 20 per cent.

Warming air, then, increases the capacity (the jar becomes taller), and, since the actual remains the same, the relative lumidity is reduced for the jar becomes relatively less full.

The dryness of the air in our houses in the winter illustrates the effect of heating air. Outside air at a temperature, say, of $10^{\circ}$ and with a relative humidity of 75 per cent (represented by C, Fig. 2), when drawn into our houses and heated to $70^{\circ}$, has its relative humidity reduced to about 10 per cent (represented by I, Fig. 2).

\section{Effect of the Cooling of Air on the Relative Humidity}

When air is cooled its capacity is reduced, as earlier stated, that is the sides of the jar are lowered. Air, for example, at $90^{\circ}$ (possible humidity 14.81 grains) having a relative humidity of 50 per cent (the actual then is 7.4 grains and is represented by A, Fig. 3), if cooled to $80^{\circ}$, has its relative humidity increased. At $80^{\circ}$ (represented by B, Fig. 2) the humidity has become 7.4 divided by 10.95 , or 68 per cent. At $67^{\circ}$ the air reaches the saturation point, that is the sides of the jar have been lowered to the point where the actual equals the possible humidity. In further cooling from $67^{\circ}$ to $60^{\circ}$ precipitation takes place, the amount being the difference between 7.4 grains, the possible humidity at $67^{\circ}$, and 5.76 grains, that at $60^{\circ}$ (represented by D, Fig. 3). Since at $60^{\circ}$ the actual equals the possible humidity (the jar is still full), the relative humidity is 100 per cent. In cooling from $60^{\circ}$ to $50^{\circ}$ there is further precipitation, visualized as the difference in the eapacity of the jar at $60^{\circ}$ (D, Fig. 3) and the jar at $50^{\circ}$ (E, Fig. 3).

Cooling air, then, increases its relative humidity (the sides of the jar are lowered) until saturation point is reached (the sides are lowered until the jar is full). Further cooling results in condensation or precipitation (some of the water vapor in the jar runs over because the sides are lowered), the relative humidity remaining 100 per cent (still the jar remains full). 


\section{Humidity Changes in the Passage of Air Across a Mountain}

These two laws, regarding the effect of heating and cooling air, find their illustration in nature in the changes that take place in the humidity of air during its journey over a mountain. Let us imagine a mass of air (A, Fig. 4), having a relative humidity of 75 per cent, moving from sea level up a mountain slope. The ascending air is cooled by expansion (adiabatic cooling), ${ }^{1}$ and this cooling reduces the capacity (the sides of the jar are lowered). At $B$ the air reaches saturation point (the sides of the jar are lowered until the jar is full). From B to the top of the mountain

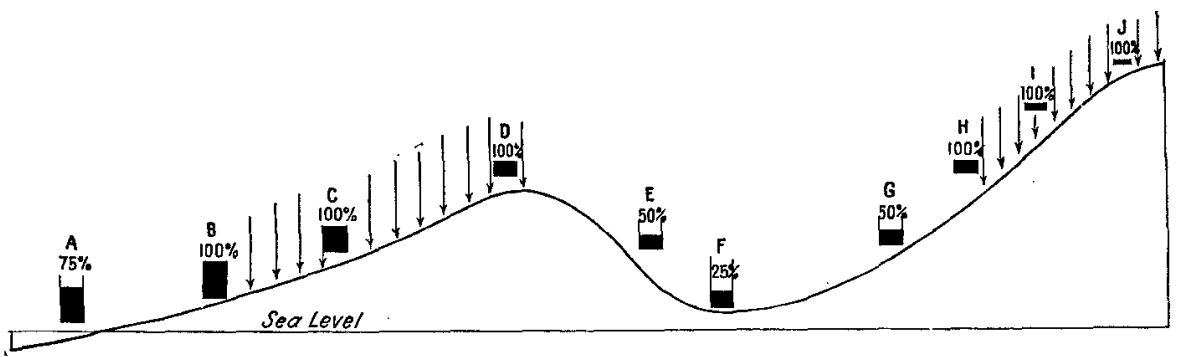

FIG.4-Diagram illustrating changes in the humidity of air in its passage across mountains from sea level.

precipitation results. At $\mathrm{D}$ the capacity has been much reduced (the sides of the jar have been much lowered), yet the air is saturated. In the descent from $\mathrm{D}$ to $\mathrm{F}$ the air is warmed $5.2^{\circ} \mathrm{F}$. for every 1,000 feet. This warming of the air increases the capacity (the sides of the jar rise), and thus the air becomes dry. In the ascent of the second mountain theoretically no precipitation takes place until $H$ is reached (at the same elevation as D), but above this point cooling results in further condensation (visualized as the result of a lowering of the sides of the jar): At $J$, although the relative humidity is 100 per cent, little actual water vapor remains.

From the diagrams it is evident that precipitation does not take place on the windward slopes of a mountain until the ascending air is cooled to saturation point. The windward sides of the mountains tend to be wet because the air is ascending and cooling, the leeward are dry because the air is descending and warming.

1 Cooling is at the rate of $5.2^{\circ} \mathrm{F}$. per 1,000 feet until saturation point is reached. Condensation results in the liberation of latent heat, and thus the rate of reduction of temperature is thence much lessened. 
The statement that the lee side is dry because the air has lost its moisture on the windward side is a poor way to put it, for rain falls on the windward slopes of the second mountain that lie above the altitude of the first, and it would fall on those of a third mountain if it were higher than the second.

\section{THE SCHOOL PROBLEM IN HAWAII}

Vaughan MacCaughey, Superintendent of Public Instruction in Hawaii, has recently described the "polyglot and polychrome" character of the schools of Hawaii (The Racial Elements in Hawaii's Schools, Mid-Pacific Magazine, September and October, 1919). The outstanding circumstances determining this character are, first, the rapid decadence of the native Hawaiian in contact with modern civilization; second, the agricultural development of the islands by Europeans and Americans; third, the demand for plantation labor (compare the first article in this number of the Journal, Tropic Isles in the Pending Settlement). The result is summarized by Mr. MacCaughey: "Hawaii presents the remarkable picture of a thin veneer of white Americans overlaying and controlling a dark-skimned population, predominantly alien, Asiatic, male, landless, homeless, non-Christian, non-Englishspeaking, and illiterate." There is, however, a considerable and increasing population of school age and an analysis of this school population exhibits the educational problem in concrete form. Percentage enrollment according to races in the schools for 1917 is thus: Hawaiian, 9; part-Hawaiian (mother Hawaiian), 13; Japanese, 40; Chinese, 10; Koreans, 1.3; Portuguese, 15; Spanish, under 2; Porto Ricans, 3; Filipinos, 1.5; Russians, Germans, British, about 1.3; Americans (whites of American ancestry), 4.6.

The percentage of Hawaiians is diminishing rapidly; it has decreased over 70 per cent during the last two decades; the small number of Spaniards is also declining. The Portnguese enrollment is large. Portuguese laborers were introduced into the islands at a comparatively early date; they now constitute the chicf "white" labor. But by far the most significant feature of the 